\title{
The Effects of ICT Environment on Teachers' Attitudes and Technology Integration in Japan and the U.S.
}

\author{
Kodai Kusano, Sarah Frederiksen, LeAnne Jones, \\ and Michiko Kobayashi \\ Southern Utah University, Cedar City, Utah, USA
}

kusano.suu@gmail.com, sarahfrederiksen@suumail.net, leanne.jones3369@gmail.com, kobayashi@suu.edu,

\author{
Yui Mukoyama, Taku Yamagishi, Kengo Sadaki, \\ and Hiroki Ishizuka \\ Hokkaido University of Education, Asahikawa, Japan \\ pyui.m0506@gmail.com, \\ yellowblockworm@gmail.com, \\ greatkengo7@gmail.com, ishizuka0040@gmail.com
}

\section{Executive Summary}

The present study analyzes the effects of Information and Communication Technology (ICT) environment on teachers' attitude toward technology integration in Japanese and U.S. elementary schools. Teacher's attitude plays an important role in influencing the effectiveness of ICT education from a variety of perspectives. A number of studies have been done regarding teachers' attitude toward ICT, but there is very little research concerning international comparisons. The interest of observation in the present paper is the cross-cultural comparison between Japanese elementary school and U.S. elementary school teachers. The purpose of the paper is to identify the factors that affect teachers' perception of ICT and how they differ between the two countries.

Past research supports the usefulness of technology for students to engage in collaborative learning. Also, when teachers view technology as a possible asset, the effectiveness of ICT is at maximal. Research in the field of ICT has provided evidences of a positive impact on students' learning, but elementary school teachers may have mixed opinions about the use of technology. From the latest statistical analysis and literature reviews, it appears that Japan may be more hesitant to ICT education on societal and individual levels.

Material published as part of this publication, either on-line or in print, is copyrighted by the Informing Science Institute. Permission to make digital or paper copy of part or all of these works for personal or classroom use is granted without fee provided that the copies are not made or distributed for profit or commercial advantage AND that copies 1) bear this notice in full and 2) give the full citation on the first page. It is permissible to abstract these works so long as credit is given. To copy in all other cases or to republish or to post on a server or to redistribute to lists requires specific permission and payment of a fee. Contact Publisher@InformingScience.org to request redistribution permission.
The technology acceptance model (TAM) was utilized to identify the teachers' perceived ease of use and usability (PEUU), perceived usefulness (PE), and attitudes toward using technology (AT). The demographic and environmental sections (gender, age, teaching experience, the technology availability, and the frequency of ICT use) were added in the survey to examine additional factors that may affect the 
teachers' attitude toward ICT. The data was collected from the teachers at the elementary schools in Hokkaido (northern Japan) and in southern Utah in the U.S.

Independent t-tests analysis showed that the U.S. teachers had more positive PEUU, PU, and AT than did the Japanese teachers. Chi-square analysis on the ICT environmental factors revealed that the U.S. teachers were provided with richer technology environments. Overall, the U.S. teachers' use of interactive boards, number of computers, and use of computers outnumbered the Japanese counterparts to a great extent. Multiple regression analysis between the demographics and the TAM indicated that the younger U.S. teachers' age significantly predicted the positive PEUU, and the Japanese gender was a significant predictor of PEUU, PU, and AT (male participants answered more positively). Multiple regression analysis between ICT environments and the TAM showed that the number of interactive boards in class was a strong predictor of Japanese teachers' PU and AT, and the number of computers in a lab significantly predicted the Japanese teachers' AT. In addition, the U.S. teachers' PEUU significantly predicted the computer use.

One limitation arose in the present study regarding the sampling equivalence between the U.S. and Japan. In the U.S. the majority of teachers were female but that was not the case in Japan. Diversity of the U.S. education is a challenging factor in comparing with Japanese education in which curriculum tends to be homogeneous throughout the country. Nevertheless, the present study found significant relationships in the teachers' attitudes, the quality of ICT environments, and other factors that affect their perceptions of ICT between Japan and the U.S. As the popularity of ICT education increases worldwide today, the U.S. teachers' positive beliefs about ICT and better quality of technology equipment may put the U.S. students in an advantaged position compared to the Japanese students.

Keywords: ICT, Teacher's attitude, and Technology integration.

\section{Introduction}

The utilization of technology in the elementary classroom is becoming increasingly vital in a global society. There are many benefits to using technology as an educational tool. Technology helps students visualize abstract ideas and makes it easy to find reliable information (Qing, 2007). Students' motivation and confidence are increased when technology is integrated into classroom instruction (Mouza, 2005; Torff \& Tirotta, 2010). Computer engagement also improves student's academic achievement (House, 2012; Mercier \& Higgins, 2013). A number of Web 2.0 technologies and open sources are currently available. Teachers at any grade level can easily create collaborative activities for students on the web (Holcomb \& Beal, 2010; "IRA members embrace," 2011). For example, the use of blogs for peer feedback improves elementary student's writing quality (Chen, Liu, Shih, Wu, \& Yuan, 2011) and a course management system helps facilitate cooperative learning in secondary classrooms (Soh, 2011). Interactive whiteboards are also common classroom technology especially in elementary schools. A study showed that students from fourth to eighth grades have a favorable attitude toward the use of interactive whiteboards and believe that interactive whiteboards have positive effects on learning (Şad \& Özhan, 2012). While most schools still use a stationary interactive whiteboard, which requires teachers to stay at the front of the classroom, a newer model with mobile technology allows teachers to move around classrooms and monitor students during instruction (Robertson \& Green, 2012). Other mobile devices, such as iPads and tablets also have much potential and can be incorporated into classroom lessons to improve student's academic performance (Cohen, 2012; Haydon, Hawkins, Denune, Kimener, McCoy, \& Basham, 2012; Sullivan, 2013). Researchers found that iPads help special needs students improve basic skills, such as reading and writing, and increase their attention and interests in learning (Fernández-López, Rodríguez-Fórtiz, Rodríguez-Almendros, \& Martínez-Segura, 2013). 
According to the report by the National Center for Education Statistics in 2009, 97\% of elementary and secondary teachers in the U.S. had at least one computer available in the classroom every day and $93 \%$ of those computers had Internet access. Although the vast majority of teachers had access to computers in the classroom, only $40 \%$ of teachers said that they used those computers often during instructional time (Gray, Thomas, \& Lewis, 2010). On the other hand, in Japan, the rate of regular classrooms equipped with computers is 35\% (MEXT, 2011). Also, only about 30\% of teachers in Japan are provided computers by the school (Shimizu, Yamamoto, Horita, Koizumi, \& Yoshii, 2007). The Internet accessibility rate in Japanese schools is $99.99 \%$. Nevertheless, the rate of teachers who use computers and the Internet in classes is about $50 \%$, as is the rate of teachers who have confidence in using computers in classes (Shimizu et al., 2007).

The attitude of the teacher toward using technologies in the classrooms is a major factor in how successful technology integration will be (Tabata \& Johnsrud, 2008). Voogt (2010) found that teachers who use technology extensively in their lessons tend to have a high level of confidence in pedagogical technology skills and focus on a learner-centered approach. They are more engaged in professional development activities and collaboration with colleagues than teachers who don't use technology very often. A number of factors must be accounted for during analysis of teachers' negative attitudes toward technology integration. In the US, some influential factors identified by past research include computer anxiety, perceived importance of computers, computer enjoyment, and the time commitment to learn new technology and teach it to the students (Christensen, 2002). The experience of technology use affects teachers' anxiety and attitude, and in particular, the higher the frequency of such experiences is, the more it affects anxiety and attitude (Takayama, 1993). Teachers' fears of being replaced by technology also create negative attitudes (Qing, 2007). While most teachers believe technology integration in the classroom will enhance their instruction, many consider the training they receive in order to utilize new technology insufficient, and available technology in schools is limited (Kazu, 2011). The technology training is often offered at inconvenient times or at other locations on different computers than those used in the classroom (Hixon \& Buckenmyer, 2009). Although training experiences in themselves do not directly affect anxiety and attitude toward technology, they have indirect effects on anxiety and attitude through the mediation of other factors such as daily use of computers as a result of having training (Takayama, 1993). Schrum and Levin (2013) examined successful professional development models for technology integration from eight exemplary schools. Through observations and interviews, they identified four critical factors for successful technology training. Those factors include formal district level activities, opportunities for summer workshops, informal professional development (e.g., peer assistance) and individual teacher development (e.g., taking graduate level courses and building professional learning communities). Furthermore, research shows that teachers' pedagogical beliefs (e.g., philosophies of teaching and learning) are correlated to their technology integration (Kim, Kim, Lee, Spector, \& DeMeester, 2013). In order to change teachers' beliefs, schools must develop strong leaderships. Also, school principals should not only be an official supervisor, but be a personal advisor to provide assistance to individual teachers and staffs (Kim et al., 2013).

Businesses around the world have embraced technology, yet many schools preparing the workforce of the future are not making the same strides. Baule (2007) suggests that in order for teachers to use technology effectively, "the technology must be easy to use; it must be engaging and flexible; and it must provide results" (Action Research section, para. 3). Teachers have the inherent ability to shape future generations. When teachers have positive attitudes toward computers, students' perceptions of computers are also positive (Christensen, 2002). Although most teachers in the U.S. have ready access to technology in the classroom, many do not use it effectively during instruction (Gray et al., 2010). Even teachers with a high level of technological competence and confidence still relied on a traditional teacher-centered approach (Prestridge, 2012). Further investigation is warranted to decipher factors that affect teachers' attitudes towards technology. 
The purpose of the study is to examine teachers' attitudes and technology integration in U.S. and Japanese elementary schools. Nearly $75 \%$ of people both in Japan and the U.S. have access to a computer at home and use the Internet (Suzuki, 2012; U.S. Census 2010). However, when it comes to technology integration in the classroom, Japanese schools tend to take more conservative approaches than US schools (Salcito, 2010). Traditionally, Japanese classrooms are teachercentered and students are expected to be quiet, whereas US classrooms emphasize collaboration and open discussion (Takeya, 1992). Morrone (2012) attributes Japan's stagnation in integrating technology to the Japanese university entrance exam that dictates the curriculum in Japanese secondary education. The Japanese university entrance exam tends to be based on the conventional content and methods; therefore, it keeps everything new and innovative like learning with technology off the lesson contents in high schools.

In Japan, students are tracked at the end of $9^{\text {th }}$ grade according to academic ability and required to take high school entrance exams. Research shows that Japanese students at the top ranked high schools tend to use computers in the classroom less frequently than those in other schools. Also, elementary students in the large cities tend to use computers more often than those living in the rural areas, while this trend is reversed in middle grade and high school levels (Benesse Educational Research and Development Center, 2008). In the US, the frequency of technology use in the classroom does not differ between elementary and secondary schools both in the city and the rural district (Gray et al., 2010).

In addition, a study by Joshi and his colleagues (Joshi, Pan, Murakami, \& Narayanan, 2010) has shown that Japanese kindergarten teachers were more skeptical and unsure of the benefit of computers. They believed that hands-on, sensory experience should be more emphasized in developing young children's performance compared to the U.S. teachers. Jung, Kudo, and Choi (2012) also claimed that excessive online collaborative activities tend to have negative effects on Japanese learners and cultural differences must be considered in designing instructions. Further, Elwood and MacLean (2012) compared student's willingness to use technology in Japan, Malaysia, and Cambodia. Their study revealed that students' technology attitudes are different, depending on the country.

In summary, various factors affect teacher's technology integration. Past research suggests that cultural factors may also influence teachers' use of technology in the classroom, as well as their technology attitudes. Thus, the present study seeks to answer the following questions, "What are factors that affect elementary teachers' attitudes toward using technology in the classroom and how do attitudes compare and differ between Japan and the U.S., which are two technologically advanced nations but are different in teaching traditions? Does the amount of technology used differ, and if so, how often and what type?" The study will help us find what changes need to occur to improve teacher attitudes and perceptions towards technology to allow for further integration in the classroom.

\section{Methods}

In the present study, the researchers utilized the teachers' technology attitudes survey developed by Holden and Rada (2011). Their survey is based on earlier research on the technology acceptance model (TAM). Davis (1989) first introduced the TAM. He claimed that perceived ease of use and perceived usefulness predict an individual's intention to use technology as well as actual usage behavior. His theory has been recognized and studied by many researchers. Holden and Rada expanded the TAM and revised the original scale by adding usability elements to the perceived ease of use. Their study showed that the revised scale with perceived ease of use and usability influenced the TAM components more than the original scale with perceived ease of use only. 
In this study, several additional items also have been included in order to examine the classroom environments and teachers' technology usage in their schools. The survey consists of five sections: demographics (gender, age, teaching experience), technology availability (the number of interactive boards, computers in class and lab), frequency of ICT use (computer, internet, interactive board), perceived ease of use and usability (PEUU), perceived usefulness (PU), and attitudes toward using technology (AT). The PEUU, and PU were assessed using a seven-point Likert scale $(1=$ strongly disagree, $2=$ moderately disagree, $3=$ somewhat disagree, $4=$ neutral, $5=$ somewhat agree, $6=$ moderately agree, $7=$ strongly agree). The AT was assessed using a sevenpoint semantic differential scale (i.e., good - extremely, quite, slightly, neutral, slightly, quite, extremely_bad) (Holden \& Rada, 2011).

A group of researchers in the U.S. and Japan collected data separately. The survey was translated into Japanese for Japanese participants. Participants in the U.S. were recruited from elementary teachers at seven different schools in Utah. All participating schools in the U.S. were located in rural areas and the student populations in each school were between 500 and 600 . A majority of teachers in those schools were White. Approval from the superintendent of the school district was obtained via email, and the mentor faculty contacted each elementary school principal to explain the study. After obtaining permission from school principals, the U.S. researchers visited each school and distributed the survey. Japanese participants were recruited from elementary teachers in Hokkaido, Japan. The Japanese researchers collected their data from teachers of different schools in Hokkaido by (1) visiting two schools in Asahikawa city, a public elementary school and an attached school to a university of education, (2) attending school teachers' meetings with participants from different schools in the city, and (3) distributing the questionnaire set up in the SNS specifically constructed for elementary teachers in Hokkaido. Student populations in most participating schools ranged from 200 to 500 .

According to the World Databank database, the U.S. and Japan are the top two countries for technology expenditures (Orfano, 2010). In the U.S., the state government allocates technology budgets to each school based on the number of students. Therefore, technology expenditures in schools can be different, depending on the state. Utah has been recognized as one of the top states in the use of digital technologies in the governments for the past several years (Center for Digital Government, 2012). Therefore, technology accessibility in Utah is higher than that of other states. In Japan, the Ministry of Education, which is equivalent to the U.S. Department of Education, is in charge of technology expenditures for all schools in Japan and allocates the budgets, which is based on the number of students (MEXT, 2011). Thus, technology accessibility in schools is more likely to be the same or similar throughout Japan.

All teacher participants completed the survey voluntarily and remained anonymous. Data were collected from April to June 2012. Chi-squared, t-test, and regression analysis were conducted to examine the data.

\section{Results}

\section{The Participants' Characteristics}

Table 1 shows a summary of participants' characteristics in the U.S. and Japan. In the U.S., 99 elementary teachers participated in the study $($ Male $=11$, Female $=88)$. The participants' ages were distributed among 22-30 (19.2\%), 31-39 (24.2\%), 40-48 (23.2\%), 49-57 (24.2\%), and $\geq 58$ (9.1\%). More than half of the U.S. participants reported having 6-10 years or 16 plus years of teaching experience (29.3\% respectively). In Japan, 67 elementary teachers participated in the study (Male=32, Female=35). The participants' ages were distributed among 22-30 (35.8\%), 31- 
39 (28.4\%), 40-48 (26.9\%), and 49-57 (9.0\%). Also, teaching experiences were distributed among 1-5 years $(31.3 \%), 6-10(20.9 \%), 11-15(13.4 \%)$, and over $16(34.3 \%)$.

Table 1: Participants' Demographics

\begin{tabular}{|c|c|c|c|}
\hline & Items & $\begin{array}{c}\text { Percent }(\mathrm{N}) \\
\text { U.S. }\end{array}$ & $\begin{array}{c}\text { Percent }(\mathrm{N}) \\
\text { JP }\end{array}$ \\
\hline \multirow[t]{2}{*}{ Gender } & Female & $88.9 \%(88)$ & $52.2 \%(35)$ \\
\hline & Male & $11.1 \%(11)$ & $47.8 \%(32)$ \\
\hline \multirow[t]{5}{*}{ Age } & $22-30$ & $19.2 \%(19)$ & $35.8 \%(24)$ \\
\hline & $31-39$ & $24.2 \%(24)$ & $28.4 \%(19)$ \\
\hline & $40-48$ & $23.2 \%(23)$ & $26.9 \%(18)$ \\
\hline & $49-57$ & $24.2 \%(24)$ & $9.0 \%(6)$ \\
\hline & $\geq 58$ & $9.1 \%(9)$ & $0 \%(0)$ \\
\hline \multirow[t]{4}{*}{ Teaching Experience } & $1-5$ years & $20.2 \%(20)$ & $31.3 \%(21)$ \\
\hline & $6-10$ years & $29.3 \%(29)$ & $20.9 \%(14)$ \\
\hline & $11-15$ years & $21.2 \%(21)$ & $13.4 \%(9)$ \\
\hline & $\geq 16$ years & $29.3 \%(29)$ & $34.3 \%(23)$ \\
\hline
\end{tabular}

\section{Independent T-Tests on PEUU, PU, and AT}

Factor scores were used to calculate the average scores of PEUU, PU, and AT, and independent ttests were used to compare the U.S. and Japan. The results showed significant differences between the two countries in all three categories. The U.S. participants were more positive for PEUU, $t(164)=-6.164, p<.001, \mathrm{PU}, t(164)=-8.046, p<.001$, and AT, $t(89.31)=-6.571, p<.001$ than Japanese participants.

\section{Differences in ICT Environment and Technology Usage}

The results of chi-square tests demonstrated that the ICT environment and technology usage differ between the two countries (see Table 2). The significant differences were found in the following categories: the number of interactive boards in class, the number of computers in class, frequency of computer use, frequency of Internet use, frequency of interactive board use. $\left(\chi^{2}=89.61\right.$, $\mathrm{df}=2, \mathrm{p}<.01, \chi^{2}=88.60, \mathrm{df}=6, \mathrm{p}<.01, \chi^{2}=61.55, \mathrm{df}=3, \mathrm{p}<.01, \chi^{2}=43.19, \mathrm{df}=5, \mathrm{p}<.01, \chi^{2}=77.14, \mathrm{df}=5$, $\mathrm{p}<.01$, respectively). The U.S. schools were better equipped in terms of ICT and the teachers had more access to ICT than the Japanese counterparts. About $85 \%$ of the U.S. participants said they have interactive boards in their classrooms, whereas less than $15 \%$ of the Japanese participants said they do. Over $90 \%$ of the U.S. participants have at least one computer in their classrooms, while $65 \%$ of the Japanese participants said there was no computer in the classroom (see Figures $1-5)$. 
Table 2. Chi-Square Tests: ICT Environment and Technology Usage

\begin{tabular}{llll}
\hline & $\chi^{2}$ & $d f$ & $N$ \\
\hline Interactive Board in Class & $89.61^{* *}$ & 2 & 177 \\
Number of Computer in Class & $88.60^{* *}$ & 6 & 178 \\
Number of Computer in Lab & 7.14 & 3 & 177 \\
Use of Computer & $61.55^{* *}$ & 5 & 176 \\
Use of Internet & $43.19^{* *}$ & 5 & 174 \\
Use of Interactive Board & $77.14^{* *}$ & 5 & 172 \\
\hline
\end{tabular}

$* \mathrm{p}<.05 * * \mathrm{p}<.01$

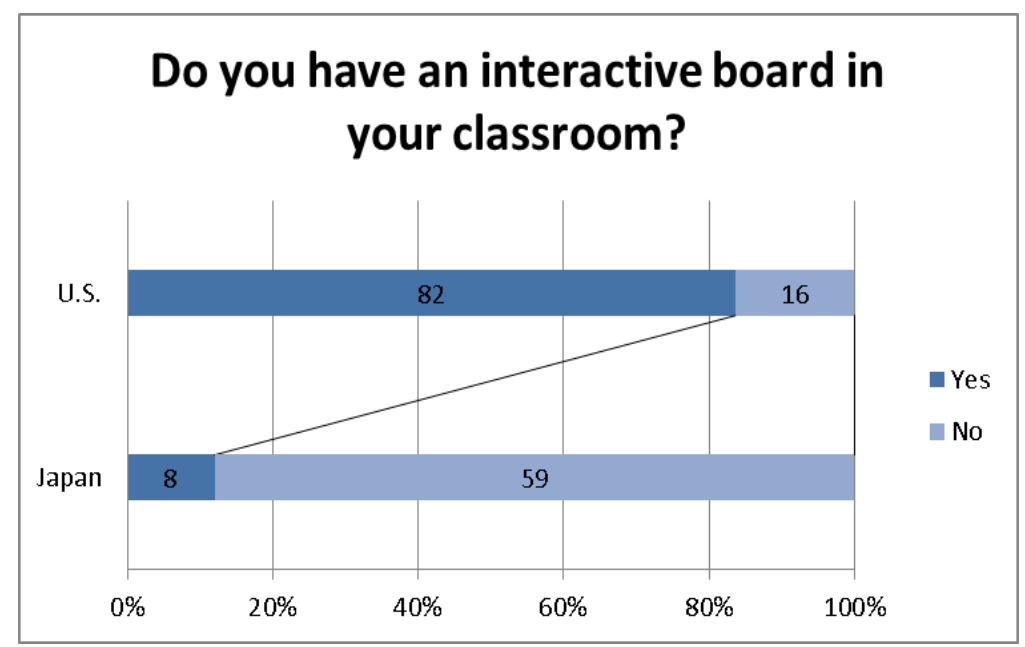

Figure 1: The number of interactive boards in class

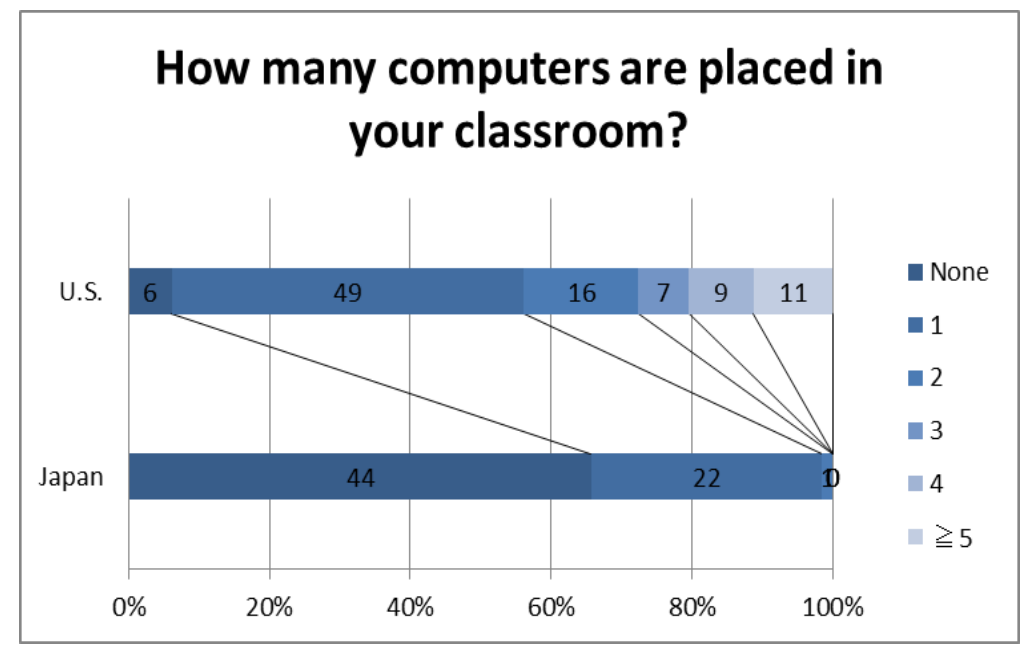

Figure 2. The number of computers in class 


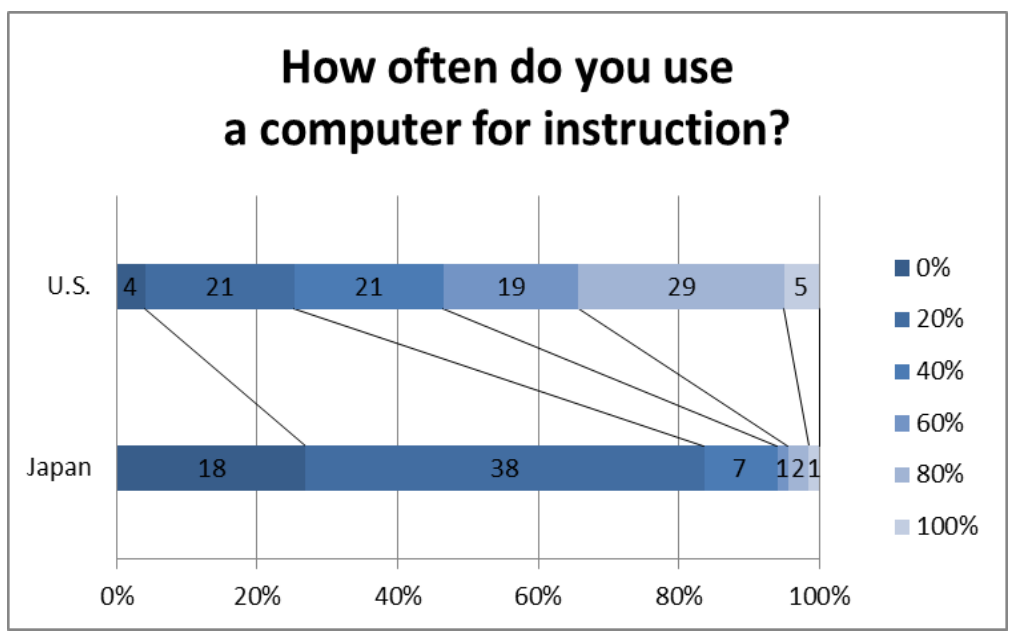

Figure 3. Frequency of computer use

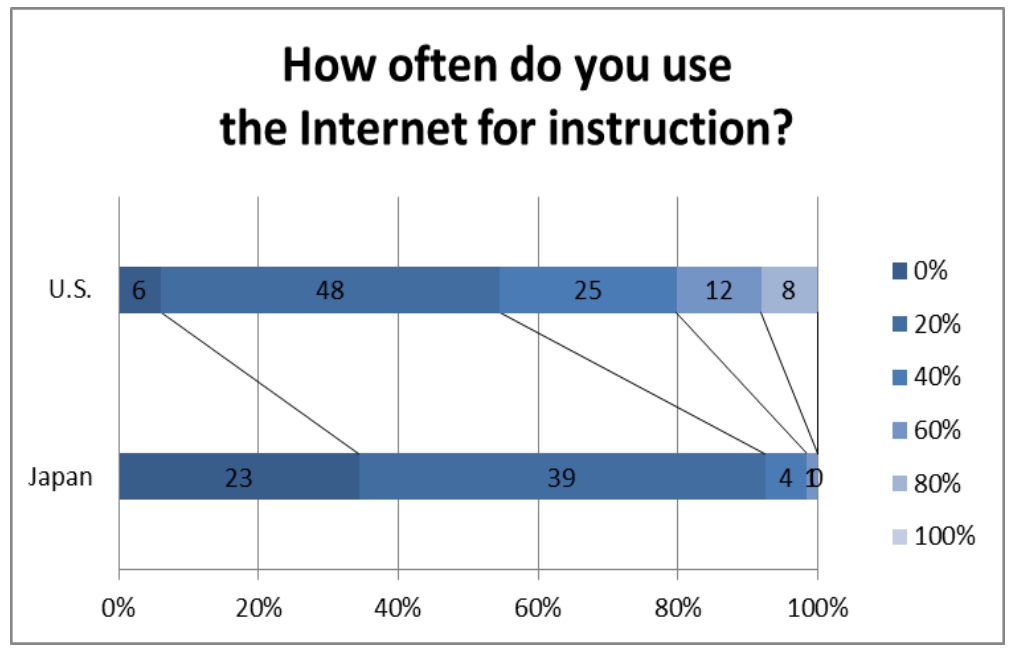

Figure 4. Frequency of Internet use

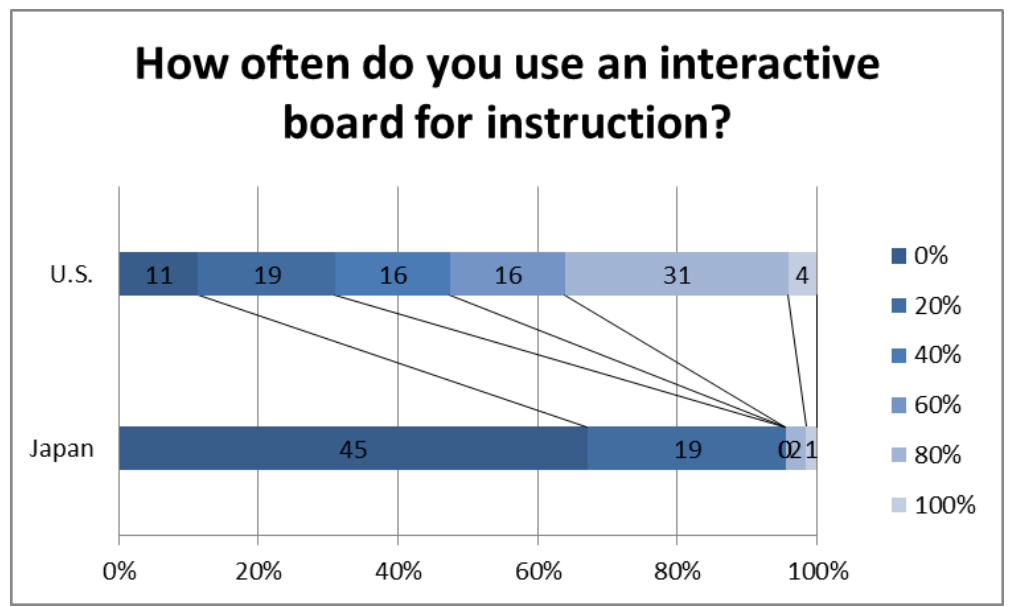

Figure 5. Frequency of Interactive board use 
With regard to the frequency of technology usage, the differences were also significant. While $28 \%$ of the U.S. participants used a computer for $80 \%$ of their instructional time, only $3 \%$ of the Japanese participants used a computer as often for instruction. Nearly half of the U.S. participants used the Internet for more than $40 \%$ of their instructional time, but only $7 \%$ of the Japanese participants used it as much. Furthermore, about $67 \%$ of the U.S. participants used interactive boards at least $40 \%$ of their class time, whereas only $5 \%$ of the Japanese participants used interactive boards as often.

\section{Predictors of PEUU, PU, and AT}

Multiple regressions were used to investigate to what extent teachers' demographics and ICT environments explain the variability of PEUU, PU, and AT respectively (see Table 3). The regressions for PEUU showed that all variables together explained $18.3 \%$ of the variance for the U.S. $\left(\mathrm{R}^{2}=.183, F(6,90)=3.37, p=.005\right)$ and $22 \%$ for Japan $\left(\mathrm{R}^{2}=.22, F(6,60)=2.82, p=.018\right)$. The coefficients of independent variables suggested that the U.S. teacher's age significantly predicted the PEUU ( $\beta=-.29, p=.003$ ), which means age is inversely proportional to PEUU, as did the number of computers in class in the U.S. $(\beta=.11, p=.048)$, which means the number of computers in class is directly proportional to PEUU. In Japan, gender was a significant predictor for PEUU ( $\beta=-.49$, $p=.033)$.

No significant results for PU and AT were found in the U.S. However, in Japan, gender ( $\beta=-.46$, $p=.039)$ and the use of interactive boards in class $(\beta=-.76, p=.021)$ were identified as strong predictors for PU. The existence of interactive boards in class affects positively on PU in Japan. The regression also revealed that all variables together significantly explained $27.8 \%$ of the variance in AT for the Japanese participants $\left(\mathrm{R}^{2}=.278, F(6,60)=3.85, p=.003\right)$. In addition, gender $(\beta=-.57$, $p=.039)$, interactive boards in class $(\beta=-.104, p=.01)$, and the number of computers in lab $(\beta=.68$, $p=.007)$ were identified as significant predictors for the Japanese participants' AT.

Table 3. Regression: Predictors of PEUU, PU, and AT

\begin{tabular}{|c|c|c|c|c|c|c|}
\hline \multirow[b]{2}{*}{ Independent V. } & \multicolumn{2}{|c|}{ PEUU } & \multicolumn{2}{|c|}{ PU } & \multicolumn{2}{|c|}{ AT } \\
\hline & U.S. & $\mathrm{JP}$ & U.S. & JP & U.S. & JP \\
\hline Gender $($ Male $=1$, Female $=2)$ & -.31 & $-.49 *$ & -.31 & $-.46^{*}$ & .01 & $-.57 *$ \\
\hline Age & $-.29 * *$ & -.20 & -.10 & .11 & -.12 & .05 \\
\hline Teaching Experience & .08 & .22 & .10 & -.18 & .05 & -.08 \\
\hline Interactive Board in Class & -.05 & -.44 & -.16 & $-.76^{*}$ & .05 & $-1.04 *$ \\
\hline Number of Computer in Class & $.11^{*}$ & .34 & .10 & -.13 & .07 & .11 \\
\hline Number of Computer in Lab & .03 & .01 & -.08 & .16 & -.11 & $.68 * *$ \\
\hline $\mathrm{R}^{2}$ & $.18^{*}$ & $.22 *$ & .07 & .16 & .07 & $.28 *$ \\
\hline
\end{tabular}

${ }^{*} \mathrm{p}<.05 * * \mathrm{p}<.01 \beta$ were reported by unstandardized coefficients. 


\section{Predictors of Technology Usage}

The regressions for the frequency of technology use also showed some significant results (see Table 4). PEUU, PU, and AT all together explained $18 \%$ of the variance in the use of computer in the U.S. $\left(\mathrm{R}^{2}=.186, F(3,95)=7.23, p=.00\right)$, as did $21.5 \%$ in $\operatorname{Japan}\left(\mathrm{R}^{2}=.215, F(3,63)=5.75\right.$, $p=.002)$. In the U.S., PEUU was the single best predictor for the use of computer $(\beta=.63, p=.002)$, while AT was found to be a strong predictor for the computer use among Japanese participants $(\beta=.31, p=.034)$. In Japan, PEUU, PU and AT all together significantly explained $14 \%$ of the variance in the use of the Internet $\left(\mathrm{R}^{2}=.142, F(3,63)=3.47, p=.021\right)$.

Table 4. Regression: Predictors of Frequency of Technology Use in Classroom Instruction

\begin{tabular}{lcccccc}
\hline & \multicolumn{2}{c}{ Computer Use } & \multicolumn{2}{c}{ Internet Use } & \multicolumn{2}{c}{ Interactive Board } \\
\cline { 2 - 7 } Independent V. & U.S. & JP & U.S. & JP & U.S. & JP \\
\hline PEUU & $.63^{* *}$ & .18 & .25 & -.00 & .41 & .02 \\
PU & .11 & -.03 & -.09 & .04 & -.32 & .12 \\
AT & -.07 & $.31^{*}$ & -.20 & .19 & -.53 & .13 \\
$\mathrm{R}^{2}$ & $.19^{* *}$ & $.22^{* *}$ & .06 & $.14^{*}$ & .07 & .07 \\
\hline
\end{tabular}

$* \mathrm{p}<.05 * * \mathrm{p}<.01 \quad \beta$ were reported by unstandardized coefficients.

\section{Discussion}

The purpose of the present study is a cross-cultural comparison between the United States and Japan in order to identify factors that affect the attitudes of teachers towards the use of technology in the classroom.

Comparison by chi-square contingency analyses of the ICT environment and the frequency of ICT use showed that overall the U.S. teachers had more access to the ICT in classroom and use them more often for instruction than the Japanese teachers. These results were consistent with the past research conducted in 2009 in the United States by the National Center for Education Statistics and the MEXT study conducted in Japan in 2011.

One notable finding about demographic data is that the Japanese teachers' gender significantly predicted PEUU, PU, and AT, while the U.S. teachers' gender did not. This may be because of the different proportions of gender in elementary school between Japan and the U.S. The majority of the U.S. teachers were female, but the Japanese teachers were almost equally distributed among female and male. The slope of the regression also indicated that the male teachers better predict PEUU, PU, and AT in both countries, even though the U.S. data did not show significant results. Another finding is that the U.S. teachers' age significantly predicted PEUU. The negative slopes of the regression clarified that the younger age predicted more positive PEUU, suggesting that even in the U.S. there seems to be a generation gap between teachers brought up in technology-rich environment and pre-technology time. This finding supports the study by Inan (Inan \& Lowther, 2010) in that teacher's age negatively affects computer proficiency and computer integration.

Regarding the ICT environment in schools, whether the teacher had an interactive board in class significantly predicted PU and AT among the Japanese teachers, whereas with the U.S. teachers it 
did not show a significant difference. This reflects the fact that newly introduced technology can affect teachers' attitude toward ICT. (Japan has just introduced one interactive board in each elementary school.) It has been also shown that PEUU in the U.S. and AT in Japan significantly predicted the frequency of computer use in class. However, the causal relationship between the school systems regarding the technology environment and the teachers' attitude toward technology use cannot be drawn from the present analysis. Also, teachers with more favorable attitude toward the use of technology encourage the school to have more technology access. Meanwhile, it is possible for the Japanese teachers to respond negatively to the use of technology regardless of the quality of ICT environments in school as the past studies suggest. Japanese teachers' negative beliefs toward ICT learning may be due to the lack of information about the research in the field of early childhood education (Joshi et al., 2010). Further research should explore the causal connection between the quality of technology environments and the teachers' attitudes, beliefs, and the possible improvements in the classroom on cross-cultural comparisons as well as the domestic comparisons.

\section{Limitations}

The current study measured the use of many types of ICT aids that can be utilized in the classroom such as interactive whiteboards, iPads, computers, and internet use. In comparison, many other studies evaluate the use of only one type of technology. This limitation may give an inconsistent result if some teachers prefer certain types of technology over another.

Another limitation was the gender differences and number of surveys collected between the two countries. In the United States, female elementary school teachers outnumbered the male elementary teachers to a large degree, yet in Japan, the number of female to male teachers was almost equal. Diversity of the curriculum in the U.S. education is a challenging factor to the sampling equivalence in cross-cultural comparison. Defining the appropriate representative of the U.S. culture is another issue that future studies could focus on for methodology design.

\section{Conclusion}

The results of the current study suggest that when schools and teachers have greater access to technological resources in the classroom, attitudes of teachers are more positive towards the use of technology and they tend to use technology to a greater degree as they educate their students. This may place Japanese students in a disadvantage compared to American students as they prepare to enter and compete in a global society.

In the present study, the population sample that responded to the surveys in both Japan and the United States came from rural regions. Future research should collect a larger population sample including a broader range of respondents from both urban and rural areas. In addition, the factors influencing Japan's lack of technological resources in public education are unclear. Therefore, future research should investigate the influences that determine Japan's lack of technological accessibility in the public education system.

Numerous recent studies have established the benefits of technology use and efficacy within the elementary classroom in preparing students for their future in a global society. The attitude of the educator towards technology use in the classroom is indicative of how well technology will be integrated in the classroom during instruction. Follow-up studies on this regard across cultures are necessary in order to find better approaches for teachers and state administrators in this rapidly changing globalized age. 


\section{References}

Baule, S. (2007). The components of successful technologies. Teacher Librarian, 34(5), 16-18.

Benesse Educational Research and Development Center. (2008). Children's Use of Computer in Schools. Retrieved from http://benesse.jp/berd/center/open/report/ict_riyou/hon/hon2_10.html

Center for Digital Government. (2012). Digital States Survey 2012. Retrieved from http://www.centerdigitalgov.com/survey/61

Chen, Y., Liu, E., Shih, R., Wu, C., \& Yuan, S. (2011). Use of peer feedback to enhance elementary students' writing through blogging. British Journal of Educational Technology, 42(1), E1-E4. doi:10.1111/j.1467-8535.2010.01139.x

Christensen, R. (2002). Effects of technology integration education on the attitudes of teachers and students. Journal of Research on Technology in Education, 34(4), 411.

Cohen, S. (2012). Apps meet the Common Core State Standards in writing. Teacher Librarian, 40(2), 3239.

Davis, F. (1989). Perceived usefulness, perceived ease of use, and user acceptance of information technology. MIS Quarterly, 13(3), 319-339.

Elwood, J. A., \& MacLean, G. (2012). To use or not to use: Psychometric properties of the willingness to use technology (WUT) instrument in three Asian contexts. Computers \& Education, 58(4), 1360-1371. doi:10.1016/j.compedu.2011.11.008

Fernández-López, Á., Rodríguez-Fórtiz, M., Rodríguez-Almendros, M., \& Martínez-Segura, M. (2013). Mobile learning technology based on IOS devices to support students with special education needs. Computers \& Education, 61, 77-90.

Gray, L., Thomas, N., \& Lewis, L. (2010). Teachers' use of educational technology in U.S. public schools: 2009. National Center for Education Statistics. Institute of Education Science, U.S. Department of Education. Washington DC.

Haydon, T., Hawkins, R., Denune, H., Kimener, L., McCoy, D., \& Basham, J. (2012). A comparison of iPads and worksheets on math skills of high school students with emotional disturbance. Behavioral Disorders, 37(4), 232-243.

Hixon, E., \& Buckenmyer, J. (2009). Revisiting technology integration in schools: Implications for professional development. Computers in the Schools, 26(2), 130-146.

Holcomb, L. B., \& Beal, C. M. (2010). Capitalizing on Web 2.0 in the social studies context. TechTrends, 54(4), 28-33.

Holden, H., \& Rada, R. (2011). Understanding the influence of perceived usability and technology selfefficacy on teachers' technology acceptance. Journal of Research on Technology in Education, 43(4). 343-367.

House, J. (2012). Science achievement of elementary-school students in the United States and Japan in TIMSS 2007: An assessment of the effects of technology engagement and classroom lesson activities. International Journal of Instructional Media, 39(3), 263-274.

Inan, F. A., \& Lowther, D. L. (2010). Factors affecting technology integration in K-12 classrooms: A path model. Educational Technology Research \& Development, 58(2), 137-154.

IRA members embrace Web 2.0 teaching tools. (2011). Reading Today, 28(6), 34-35.

Joshi, A., Pan, A., Murakami, M., \& Narayanan, S. (2010). Role of computers in educating young children: U.S. and Japanese teachers' perspectives. Computers in the Schools, 27(1), 5-19.

Jung, I., Kudo, M., \& Choi, S. (2012). Stress in Japanese learners engaged in online collaborative learning in English. British Journal of Educational Technology, 43(6), 1016-1029. doi:10.1111/j.1467-

8535.2011.01271.x 
Kazu, I. (2011). An investigation of factors affecting the use of educational technology in Turkish primary schools. Education, 131(3), 510-524.

Kim, C., Kim, M., Lee, C., Spector, J., \& DeMeester, K. (2013). Teacher beliefs and technology integration. Teaching \& Teacher Education, 29, 76-85. doi:10.1016/j.tate.2012.08.005.

Mercier, E. M., \& Higgins, S. E. (2013). Collaborative learning with multi-touch technology: Developing adaptive expertise. Learning \& Instruction, 25, 13-23. doi:10.1016/j.learninstruc.2012.10.004

MEXT (Ministry of Education, Culture, Sports, Science, and Technology in Japan). (2011). Gakkou ni okeru kyouiku jouhouka no jittaitou ni kansuru chosa kekka. [The survey on the actual situations of computerization of school education].

Morrone, M. H. (2012, November). Social and cultural impediments to the adoption of ICT for language learning in Japan. Proceedings from the International Conference "ICT for Language Learning" 5th edition. Florence, Italy. Retrieved from http://conference.pixelonline.net/ICT4LL2012/conferenceproceedings.php

Mouza, C. (2005). Using technology to enhance early childhood learning: The 100 Days of School project. Educational Research \& Evaluation, 11(6), 513-528.

Orfano, F. (2010). Information technology spending by country. Retrieved from http://www.brighthub.com/computing/hardware/articles/80611.aspx\#

Prestridge, S. (2012). The beliefs behind the teacher that influences their ICT practices. Computers \& Education, 58(1), 449-458.

Qing, L. (2007). Student and teacher views about technology: A tale of two cities? Journal of Research on Technology in Education, 39(4), 377-397.

Robertson, C., \& Green, T. (2012). Interactive whiteboards on the move! Techtrends: Linking Research \& Practice to Improve Learning, 56(6), 15-17.

Şad, S., \& Özhan, U. (2012). Honeymoon with IWBs: A qualitative insight in primary students' views on instruction with interactive whiteboard. Computers \& Education, 59(4), 1184-1191.

Salcito, A. (2010, December 31). Japan's progress on infusing technology into the classroom. Retrieved from http://blogs.msdn.com/b/microsoftuseducation/archive/2010/12/31/japan-s-progress-on-infusingtechnology-into-the-classroom.aspx

Schrum, L., \& Levin, B. (2013). Lessons learned from exemplary schools. Techtrends: Linking Research \& Practice to Improve Learning, 57(1), 38-42. doi:10.1007/s11528-012-0629-6

Shimizu, Y., Yamamoto, T., Horita, T., Koizumi, R., \& Yoshii, A. (2007). Current situations and future prospects for informatization of school. Japan Society for Educational Technology, 30(4), 365-374.

Soh Or. K. (2011). Cooperative learning environment with the Web 2.0 Tool e-portfolios. European Journal of Social Science, 21(1), 17-27.

Sullivan, R. M. (2013). The Tablet inscribed: Inclusive writing instruction with the iPad. College Teaching, 61(1), 1-2. doi:10.1080/87567555.2012.700339

Suzuki, Y. (2012, April 6). Technology use in Japan. [Online forum comment]. Retrieved from http://www.edutopia.org/groups/technology-tools/107602

Tabata, L., \& Johnsrud, L. (2008). The impact of faculty attitudes toward technology, distance education, and innovation. Research in Higher Education, 49(7), 625-646.

Takayama, S. (1993). An analysis on the computer attitudes for education and the computer anxiety of inservice teachers. Japanese Journal of Educational Psychology, 41, 313-323. Retrieved from http://ci.nii.ac.jp/els/110001892905.pdf?id=ART0002071515\&type=pdf\&lang=jp\&host=cinii\&order $\underline{\text { no }}=\& p p v \_$type $=0 \&$ lang $\_$sw $=\&$ no $=1334306919 \& \mathrm{cp}=$

Takeya, K. (1992). Culture shock: Schools in the U.S. and Japan. KLEIDOSCOPE. Retrieved from http://leo.stcloudstate.edu/kaleidoscope/volume3/cultureshock.html 
Torff, B., \& Tirotta, R. (2010). Interactive whiteboards produce small gains in elementary students' selfreported motivation in mathematics. Computers \& Education, 54(2), 379-383.

U.S. Census (2010). Computer and Internet Use in the United States: 2010. Retrieved from http://www.census.gov/hhes/computer/publications/2010.html

Voogt, J. J. (2010). Teacher factors associated with innovative curriculum goals and pedagogical practices: Differences between extensive and non-extensive ICT-using science teachers. Journal of Computer Assisted Learning, 26(6), 453-464.

\section{Biographies}

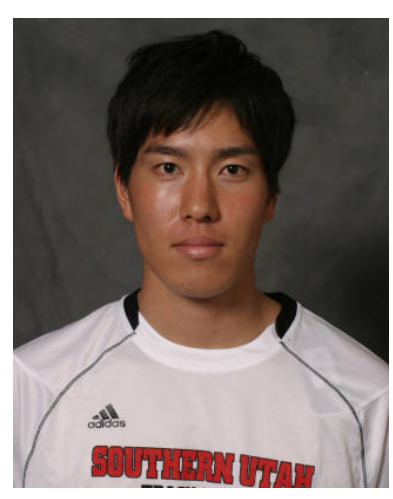

Kodai Kusano is currently a senior student at Southern Utah University, majoring psychology and physical education. He has been interested in cross-cultural research since his experience as an international student at SUU changed his outlook. He is now planning to pursue a doctorate degree in social/cognitive psychology with emphasis on cultural psychology. His research interest focuses on decision-making process among collectivistic and individualistic cultures. His career goal is to broaden not only his own perspective, but also to broaden other people's minds by studying reciprocal interaction between culture and human behavior on a variety of domains in this global society.

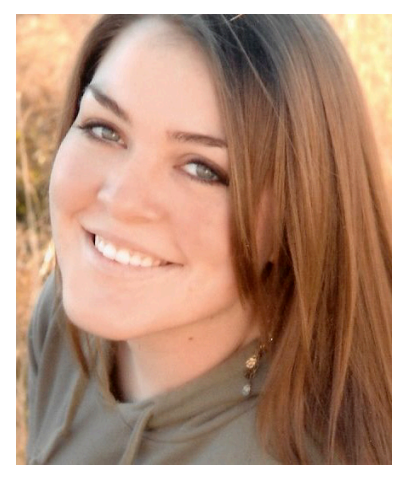

Sarah Frederiksen is currently a senior attending Southern Utah University. She is majoring in Elementary Education with an emphasis in English as a Second Language. This is her first undergraduate research completed. She strives to learn all she can about successful teaching strategies and effective instruction for students. Her research interests are driven by the curiosity to know how technology can be better utilized within a classroom setting to benefit students of all ages and languages.

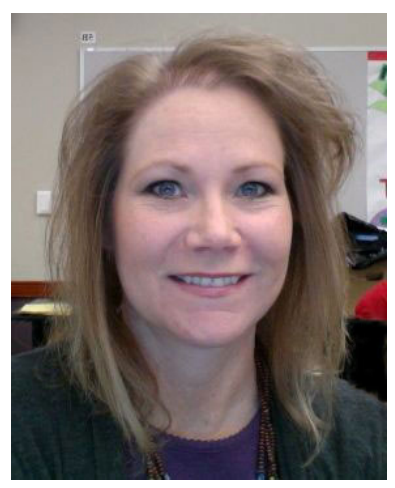

LeAnne Jones is a non-traditional student at Southern Utah University, set to graduate with her BS in Elementary Education with English as a Second Language Endorsement. She volunteered for nine years and then became employed at a local elementary school as she raised her young children. Her experiences working with children in the public education system led her to pursue her dream of becoming an elementary teacher. She has a great interest in improving the educational opportunities of children by using all available resources, including technology use in the classroom. 

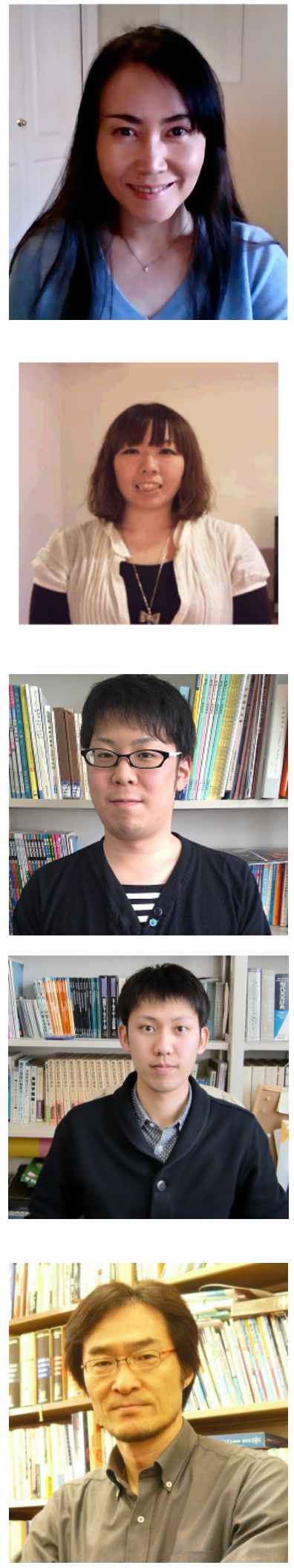

Taku Yamagishi is a graduate student at Hokkaido University of Education, Asahikawa Campus. His major is English education. His interest includes ICT, in particular, computer assisted language learning. In his past research, he focused on the essential elements in English eLearning systems and constructed an optimal system to examine the elements. He made presentations in Pacific Rim 2012 held in Japan and e-Learn 2012 in Montreal.

Kengo Sadaki is a graduate student at Hokkaido University of Education, Asahikawa Campus. His major is English education. He has an experience of working as a Japanese English teacher at elementary school for a year. His interest includes second language acquisition, especially English vocabulary acquisition of elementary school children. He has been researching the topic as the subject of his master thesis. He made presentations in Pacific Rim 2012 held in Japan.

Hiroki Ishizuka is Professor in the Department of Education at Hokkaido University of Education (HUE). He obtained his Master's degree in HUE, and finished Ph.D. course in the Department of Information Science at Hokkaido University. His research interests include language education in 3D virtual reality, technology use in language class, e-Learning system, and second language acquisition. His research work is published in leading journals including ELEED (E-Learning and Education) and JASELE Journal. His published books include an authorized junior high school English textbook and a manual of information education in secondary school. He worked as a member of the editorial board for JASELE Journal and JACET Bulletin. 